\title{
Religiosidade e Problemas com o Álcool: um Estudo de Caso
}

Religiosity and problem drinking: A case study

Marlon Xavier

Universidade do

Extremo Sul

Catarinense - UNESC 


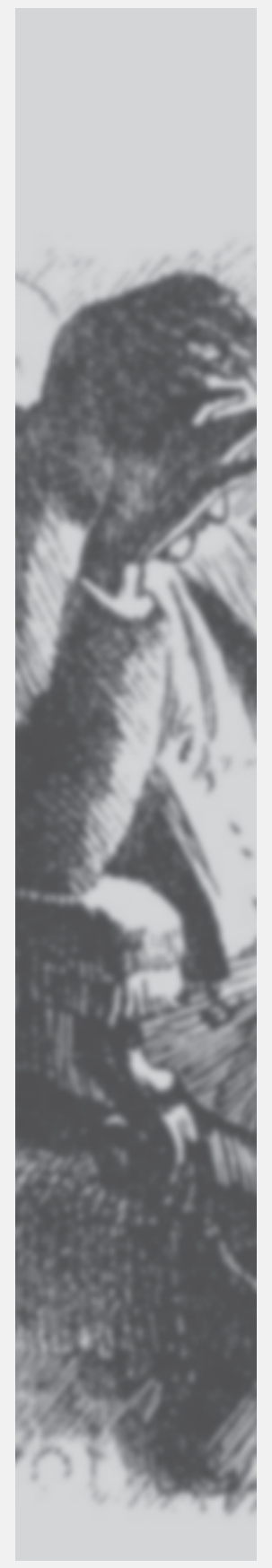

Resumo: Este estudo buscou analisar a relação entre os fatores problemas com o álcool e religiosidade. Para tanto, foi utilizado um estudo de caso único, composto por narrativas biográficas e sonhos do sujeito, um homem de mais de 50 anos. A partir desse material, buscou-se verificar como os fatores se manifestavam consciente e inconscientemente, seguindo a teoria e a metodologia de interpretação de C. G. Jung. Conscientemente, a religiosidade manifestou-se através da crença no espiritismo e no que Jung chama de religio; inconscientemente, através de uma religiosidade que chamamos de dionisíaca. O estudo demonstra que as diferentes formas de religiosidade manifestas pelo sujeito apresentaram relações complexas com os problemas com o álcool - desde incitação ao beber e acirramento dos problemas relacionados até possibilidades de resolução dos problemas. As relações do sujeito com os valores coletivos que incentivam o consumo de álcool também foram objeto de estudo. Conclui-se que a religiosidade, de maneira geral, contribuiu para uma relativização na percepção desses valores, fortalecendo uma compreensão mais individual do problema com o álcool. O estudo propõe, ainda, maior atenção ao fator religiosidade na pesquisa sobre álcool.

Palavras-chave: alcoolismo, religiosidade, Psicologia Analítica, estudo de caso.

Abstract:This study aimed at analysing the relation between the factors of religiosity and problem drinking. For such, a single case study was used, composed by dreams and biographic narratives of the subject, a man in his late fifties. Through this material, we set out to verify how the factors became manifest, both consciously and unconsciously, following C. G. Jung's theory and methodology of interpretation. Consciously, the subject displayed religiosity through a belief in spiritism and through what Jung calls religio; unconsciously, through a form of religiosity which we called Dionysian. The study demonstrates that the different forms of religiosity expressed by the subject showed complex relations with the problems related to drinking - from incitement to drink and worsening of the related problems to possibilities of resolution of the problems. The relations between the subject and the cultural values that encourage alcohol consumption were also object of investigation. As a conclusion, religiosity in general contributed to a lessening of the subject's perception of the aforementioned values, and to strengthen a more individual comprehension of the problems related to drinking. The study also proposes that more attention should be paid to the religiosity factor in alcohol and problem drinking-related research.

Key words: problem drinking, religiosity, Analytical Psychology, case study.
Conscientemente, a religiosidade manifestou-se através da crença no espiritismo e no que Jung chama de religio; inconscientemente, através de uma religiosidade que chamamos de dionisíaca.
1 Este artigo constitui-se em resumo da dissertação de mestrado defendida junto ao Programa de PósGraduação em Psicologia, enfase Psicologia Social e da Personalidade, da PUCRS. 
Desde tempos imemoriais, as religiões têm conferido ao uso de substâncias psicoativas uma importância fundamental em ritos, liturgias e mesmo em seus fundamentos. Em nossa contemporaneidade, contudo, o problema adquiriu outras proporções: as principais religiões não advogam o uso de substâncias, porém (ou talvez exatamente por causa disso) o uso de, e a adição a tais substâncias, especialmente o álcool, têm crescido enormemente, tornando-se um dos principais problemas de saúde pública no mundo.

Algumas pesquisas têm-se dedicado a investigar qual a relação entre os fatores religiosidade e uso e adicção ao álcool. A religiosidade ou espiritualidade, geralmente, é enfatizada como um elemento importante na recuperação da adicção, ou mesmo como um fator protetor fundamental contra o abuso de álcool/drogas; a prática clínica, sobretudo, demonstra a importância que vários pacientes envolvidos com tais problemáticas freqüentemente dão ao papel da religiosidade em suas vidas. Não obstante, há relativamente pouco volume de pesquisa explorando as relações entre os dois fenômenos, sendo que a tendência geral é seguir os pressupostos do paradigma vigente - materialismo, atomismo e universalismo - impondo, assim, o uso de técnicas quantitativas tão somente (como escalas e análise do comportamento).

Há várias objeções a tais tipos de estudo sendo levantadas por teóricos. Diversos autores acentuam uma crítica na hiperconfiança, demonstrada na maioria dos estudos sobre tais fatores, em correlações simples e explicações causais e lineares - pois a religiosidade é um fenômeno complexo e multidimensional, esperando-se, portanto, que suas inter-relações sejam talvez ainda mais complexas. Parece haver uma necessidade premente de estudos que levem em conta a vivência do indivíduo religioso como é sua experiência, como ele percebe sua religiosidade - e como relaciona tal fator com a problemática relacionada ao álcool, levando em conta todo o contexto de sua vida.

\section{Objetivos de pesquisa}

Este estudo buscou preencher essa lacuna, tendo como objetivos de pesquisa analisar como o indivíduo relatou, através de narrativas, o modo como vivencia a religiosidade, os problemas que tem com o álcool e como vê a relação entre tais fatores. A partir de narrativas biográficas, tomando o contexto de vida e os sonhos do sujeito com o objetivo de construir um estudo de caso, procuramos descrever e interpretar os significados que o indivíduo construiu, consciente e inconscientemente, acerca desses fatores. $\mathrm{O}$ trabalho constituiu-se em estudo de cunho exploratório, tentando identificar ou descobrir variáveis importantes e gerar hipóteses, apresentando, contudo, uma tentativa de explicação dos fenômenos à luz da teoria de Jung. Representa, para nós, a busca de uma interpretação junguiana de fatos individuais (religiosidade e problemas com o álcool) que sirva de continente à proposição de interpretações desses fatos e de suas ocorrências na esfera cultural ou coletiva.

\section{Questões norteadoras}

As questões norteadoras utilizadas foram: nas narrativas das vivências do participante, quais são os temas, padrões, categorias e sentidos salientados em relação à religiosidade e a problemas com o álcool? Estão tais padrões e sentidos conectados aos dois fatores? Se estão, de que forma essa conexão ou relação se apresenta na narrativa do participante?

\section{Revisão teórica}

Utilizamos a teoria e a hermenêutica de Jung ao longo de todo o trabalho. Para Jung, o conceito de religiosidade é vinculado a dois 
fatores: numen e religio. O numen, termo de um autor clássico, Rudolf Otto, é uma qualidade relacionada ao sagrado que desperta efeitos de reverência, fascínio e medo. Para Jung, o que caracteriza a religião é a atitude particular de uma consciência transformada pela experiência do numinoso. Jung, assim, encara a religião, ou religiosidade, como uma atitude do espírito humano, atitude que, de acordo com o emprego original do termo religio, pode ser descrita como uma consideração e observação cuidadosas de fatores dinâmicos, concebidos como potências que influenciam a consciência e, portanto, a experiência (Jung, 1938/1990, par. 982). Dessa maneira, duas conceituações são contempladas em relação à religiosidade: a mais tradicional, instituída, e a de religio.

O conceito de arquétipo, por ser caracteristicamente numinoso, vincula-se ao de numen; a experiência subjetiva do arquétipo constitui, nesse sentido. a própria experiência religiosa. $\mathrm{O}$ arquétipo possui, via de regra, um dinamismo autônomo e um telos, uma meta. Também o conceito de libido de Jung aparece conectado a religiosidade, em dois sentidos: primeiro, o caráter de numinoso depende de uma intensa carga libidinal, portada pelo arquétipo; segundo, a libido pode ser transformada em suas qualidades através do símbolo (de um investimento na esfera sexual para uma produção cultural, por exemplo). Essa transformação se dá através de ritos, mitos e cultos; portanto, para Jung, a religiosidade, na medida em que serve, pela sua riqueza simbólica, de meio de transformação de uma libido instintual em cultural, é inerente à cultura e mesmo fundamento dela (no que concorda com Cassirer, 1994, p. 153). Em relação a essa questão, Jung irá propor uma função religiosa natural do Self, o centro da personalidade global. Essa função religiosa espelha-se na busca do material arquetípico por concretização simbólica, que impele a determinadas metas - a última sendo a totalidade, ou seja, a realização do Self. A própria experiência religiosa é, assim, vista por Jung como uma vivência da totalidade.

Em relação à outra temática, os problemas com o álcool, procuramos utilizar um modelo diferente do de alcoolismo clássico: o conceito de Heather de problem drinking (1980, 1999). Esse conceito tem algumas implicações importantes:

o "problema com o álcool" não é visto como uma entidade distinta, e não há uma linha estrita que separe bebedores com problemas dos bebedores que não os têm;

- não é um fenômeno unificado; há muitos tipos de problemas; há modelos independentes de problemas com a bebida;

os problemas não pioram necessariamente com o tempo: os indivíduos entram e saem desse estado problemático causado pelo álcool várias vezes ao longo da vida;

a dependência de álcool é definida em função do comportamento do bebedor, não sendo, essencialmente, um construto biológico;

os problemas com o álcool e a dependência não são unicamente produto da psicologia ou biologia individuais; eles desenvolvem-se e mantêm-se em contextos socioculturais concretos.

Em Jung, buscamos uma explicação psicológica para os problemas com o álcool. Para a Psicologia Analítica, a religiosidade está intrinsicamente conectada à adicção ao álcool, pois, empiricamente, a substância adquire, para os adictos, um caráter religioso: como um numen, ela fascina, é irresistível e foge ao controle do indivíduo. Nesse contexto, as religiões instituídas têm importância
O conceito de arquétipo, por ser caracteristicamente numinoso, vinculase ao de numen; a experiência subjetiva do arquétipo constitui, nesse sentido. a própria experiência religiosa. 
fundamental, na medida em que servem como sistemas simbólicos que ordenam e dão forma ao processo inconsciente e ao numen dos arquétipos. Na situação contemporânea, alguns autores, entre eles Jung e Nietzsche, apontam para uma falência desse sistema simbólico - e a conseqüente substituição por outros símbolos e valores, dos quais os mais importantes são o individualismo, o hedonismo, o consumismo e o racionalismo, concretizados no homo non-religiosus (Eliade, 1959). Faltando o meio de expressão apropriado, o inconsciente e seus aspectos numinosos manifestar-se-ão em suas formas negativas, através da coerção. Apesar dessa forma negativa, tais aspectos são fundamentais ao homem e à cultura, pois carregam a necessária compensação à unilateralidade dominante. A absorção e concretização simbólica desses conteúdos apresentam-se, assim, como tarefas salutares ao indivíduo, de diferentes formas; para cumprir tais tarefas, ele necessita de religio, segundo Jung.

Após, analisamos e amplificamos um mito que contém elementos importantes para o entendimento do caso, e que, ao mesmo tempo, representa um aspecto humano fundamental que não é contemplado em sua totalidade pela cultura contemporânea: o mito dionisíaco. Para tanto, utilizamos obras de autores também clássicos, como Walter Otto (1986), Kerényi (1976, 1976a, 1983) e Vernant (1990, 1992, 2000). Os múltiplos aspectos do humano que esse mito expressa serão melhor aprofundados quando o caso for analisado.

\section{Método}

Utilizamos um delineamento de estudo de caso único, construído a partir de entrevistas em profundidade tomadas como narrativas biográficas. Procuramos discutir as proposições de alguns autores que embasam essas escolhas metodológicas. Com relação ao estudo de caso único, usamos as perspectivas teóricas de Yin (1994) e de Stake (1998). Salientamos, resumidamente, alguns aspectos propostos por esses autores: o estudo de caso único é tomado como estudo em profundidade, de caráter exploratório ou descritivo, mas também explanatório. As proposições teóricas que guiam a coleta e a análise dos dados devem ficar explícitas. A generalização dos resultados é analítica, ou seja, dá-se ao nível da teoria. A partir dessas proposições, consideramos a unidade de análise principal como o próprio indivíduo e as unidades de análise embutidas, como vivência da religiosidade e dos problemas com o álcool.

Buscamos fundamentar as escolhas metodológicas por narrativas biográficas e estudo de caso único através de alguns autores clássicos, como Geertz (1973), Bakhtin (em Todorov, 1981) e a Psicologia Cultural de Bruner (1997). Poderíamos resumir da seguinte maneira as contribuições desses autores: as narrativas e sonhos do sujeito são tomados como texto, que é carregado de significado. Esse significado - que é o objeto de compreensão, aqui - encerra a singularidade do sujeito, como ele interpreta sua realidade e sua vida, e que telos pode haver em seu comportamento. Tais autores aproximam-se, de uma forma ou outra, do pensamento de Jung, e também por isso foram utilizados.

\section{Participantes e procedimentos}

Escolhemos, intencionalmente, um sujeito como caso único por ele desejar colaborar com o trabalho, por apresentar um caso mais rico em informação (Patton, 1990) e por manifestar os fenômenos mais intensamente. Nesse sentido, o sujeito representa um caso único pela importância e unicidade de seu caso. Realizamos, então, duas entrevistas em profundidade, procurando obter uma narrativa do indivíduo acerca de sua vida, seus 
problemas com o álcool e sua religiosidade, valorizando signos, símbolos e expressão de sentimentos na linguagem, e validando como o participante constrói significados. Cabe dizer que o paciente já se encontrava em análise conosco há 6 meses (tendo participado de mais ou menos vinte e quatro sessões). A primeira entrevista foi realizada na casa do participante, a segunda, em um consultório, cada uma durando, aproximadamente, duas horas; procuramos restringir nossa participação ao mínimo possível, limitandonos a pequenas intervenções. Tais entrevistas foram consideradas como narrativas (biográficas) e constituem o material para a elaboração do estudo de caso, junto aos sonhos relatados pelo paciente e nossas anotações em sessões de análise (que consideramos como diário de campo). A partir desse material, elaboramos o estudo de caso, restringindo ou recontextualizando certas informações para respeitar o princípio de sigilo o máximo possível. Assim, os elementos biográficos do sujeito aparecerão aqui en passant, por causa tanto dos limites de um artigo quanto do sigilo.

\section{Instrumentos e material}

Entrevistas: foram feitas duas entrevistas individuais com o sujeito, posteriormente transcritas, para obtenção das narrativas biográficas.

Diário de campo: constitui-se de anotações feitas por nós ao longo das sessões analíticas, compreendendo narrações acerca de fatos ocorridos com o sujeito, percepções, vivências, atitudes e sentimentos expressos pelo mesmo. Compreende, também, algumas associações referentes ao material onírico, feitas pelo sujeito durante as sessões.

Análise dos dados: procuramos correlacionar os pressupostos teóricos - as possibilidades de leitura psicológica das narrativas biográficas e demais materiais dados por Jung - com as interpretações obtidas anteriormente, buscando a formulação de hipóteses (Yin, 1994) e a compreensão dos significados que o sujeito constrói acerca da experiência da religiosidade e dos problemas com o álcool. Essa técnica é descrita por Donald Campbell (1975) e chamada de confrontamento ou combinação de padrões (pattern matching), onde várias séries de informações provenientes do mesmo caso podem ser relacionadas à mesma proposição teórica. A interpretação de sonhos seguiu mais fielmente a hermenêutica de Jung, baseada nos conceitos de a) interpretação ao nível do sujeito, na qual os materiais oníricos são interpretados simbolicamente, como partes da psique do sonhador; b) contextualização, onde o contexto subjetivo - a história de vida do sonhador, obtida através das narrativas biográficas - e o psicológico - o tecido de associações fornecido pelo sonhador - são tomados como pano de fundo do material onírico e da própria interpretação; c) amplificação, construída pelas associações subjetivas do sonhador ou objetivas - o que a cultura humana produziu acerca de determinado símbolo onírico; d) serialização, a série de sonhos, que, por sua vez, também fornece uma espécie de contexto psíquico à interpretação.

\section{Resultados e discussão}

O sujeito tomado como estudo de caso é um homem de mais de 50 anos, que chamamos de O., que teve, ao longo da vida, diversos problemas físicos, como enxaquecas, tuberculose, hepatite, gastrite e outros. Além disso, sempre fez uso abusivo de medicamentos. Tanto os problemas físicos quanto esse uso abusivo formaram um círculo vicioso junto ao uso contínuo de álcool - pois O., às vezes, tomava muitos medicamentos porque o álcool acentuava seus problemas físicos, ou bebia porque queria aliviar sua dorde-cabeça, e assim por diante. Em determinado momento, todos os problemas 
se agravaram, bem como o uso de álcool; além disso, sua vida social foi muito prejudicada. Um ano depois, procurou ajuda psicoterápica. Depois de algum tempo em terapia, os problemas com o álcool diminuíram consideravelmente em intensidade e número.

Utilizamos, no caso, as narrativas biográficas para compreender os significados conscientes que o sujeito tece relativamente à religiosidade e aos problemas com o álcool, e a análise de sonhos para verificar os significados inconscientes. Procuramos, assim, abranger a totalidade da psique (ou o mais próximo possível dela), com todos os elementos importantes (sexualidade, religiosidade e complexos não só vinculados à religiosidade), pois a totalidade do sujeito é fundamental no entendimento dos problemas com o álcool.

O. referiu-se à sua religiosidade de diferentes formas; a partir do modelo teórico junguiano, essas formas seriam consideradas de três maneiras: a religiosidade referida conscientemente, o espiritismo; a referida pelo inconsciente, que chamamos de dionisíaca, e uma forma que embasa e, ao mesmo tempo, expande as anteriores, a religio.

A forma consciente é expressa nas narrativas; nelas, O. tece algumas relações importantes entre sua religiosidade e os problemas com o álcool. Religiosidade, para ele, significa essencialmente fé, fé no espiritismo. Essa fé envolve diversos fatores: envolve esforço, investimento e conquista; envolve conhecimento, tanto de si mesmo quanto da doutrina espírita: ele procura, incentivado pelo espiritismo, estudar o corpo doutrinário e conhecer melhor a si e aos outros - o que coloca o aspecto de religio, ou seja, uma autoreflexão constante: observar cuidadosamente a si mesmo, visando a uma harmonia consigo mesmo e com o mundo. Esse conhecimento age como uma espécie de feedback sobre a fé, segundo O. A fé também age no sentido de incentivar $\mathrm{O}$. a concretizar determinados objetivos, como se fortalecesse a vontade. Todos esses fatores formam uma espécie de rede de influência, uns alimentando os outros, ao mesmo tempo em que alimentam e são alimentados pela fé ou religiosidade. Esta também é vinculada a atitudes como modéstia, otimismo, não-competitividade e respeito a limites. A religiosidade também aparece como provedora de sentido, tanto em relação aos problemas sérios causados pelo álcool quanto em relação à própria vida, e propicia, ainda, um ideal de vida e uma meta para $\mathrm{O}$.

Todos esses elementos terão algum tipo de relação com os problemas com o álcool e com a tentativa de $\mathrm{O}$. de diminuir seu consumo. Esse objetivo é fortalecido por um conhecimento maior de si mesmo, pelo fator religio, por uma ênfase no esforço e na conquista; a modéstia e a nãocompetitividade são contrapontos à inflação relacionada ao abuso de álcool (de que falaremos mais tarde); tal objetivo também fica dentro de um maior, a meta de vida, o que contribui para sua consecução, e, por último, a questão do sentido é essencial, pois representa a força motriz de todo o processo. Concluindo, nas narrativas, fica explícita a influência da religiosidade no entendimento dos problemas com o álcool e na tentativa de O. de diminuí-los; essa influência é também prática, visto que foi aconselhado por pessoas de seu culto a buscar ajuda, a buscar terapia, e a repensar o modo como levava sua relação com a bebida.

A religiosidade que caracterizamos como dionisíaca apareceu, principalmente nos sonhos de O., em forma inconsciente e simbólica como a alegria, o esquecimento das dores, da tragédia e dos problemas vinculados ao álcool, e também como música, dança e carnaval. O caráter arquetípico de Trickster ou embusteiro aparece como uma predileção por 
ironias e piadas e pelo sofrimento autoimposto, e também nos sonhos. Tanto nas narrativas quanto nos sonhos, aparece, também, um vínculo muito forte entre o criativo e o dionisíaco, este relacionado ao álcool. A expressão mais forte desse dionisíaco, a arte escolhida por O., também é dionisíaca por excelência: o teatro.

No entanto, quando essas facetas positivas do dionisíaco não são encenadas, o trágico entra em cena: o dionisíaco força entrada de maneira brusca, querendo a liberação dos afetos e a dissolução das barreiras. O meio utilizado por O. para expressão desse dionisíaco foi o álcool; nesse sentido, o mesmo caráter religioso do dionisíaco aparece vinculado ao álcool, porém em forma negativa. A falta de concretização simbólica do dionisíaco, que seria possível através do teatro, causa uma espécie de substituição pelo álcool. Com o fracasso de O. nessa concretização, o dionisíaco fica confinado apenas ao carnaval e ao beber, o que é insuficiente. Sem a concretização na arte, o que é o cerne da religiosidade dionisíaca em O., ocorre uma possessão pelas emoções ou afetos; acontece, então, pelo poder do álcool, um típico e completo esquecimento do individual, uma fusão no coletivo - e uma conseqüente inferioridade. O problema da inflação, oriundo da falta de concretização da libido criativa, então aparece, pois que ocorre a identificação com a dinâmica arquetípica; a inferioridade torna-se ainda maior, exigindo uma grandiosidade artificial compensatória obtida através do álcool. Preso no conflito entre esses opostos, O. nada consegue criar, pois o que quer que tente fazer representa tanto uma tarefa para a qual não se sente capaz quanto algo sentido como muito reles para ele. As emoções, que, por seu turno, buscam uma realização superior, também aparecem cada vez mais caóticas e possessoras - até que o Eros (no sentido de impulso para as relações emocionais) simplesmente se recolhe, por assim dizer, quando O. abandona amigos, trabalho e lazer e dedica-se somente a beber, ou seja, o trágico entra em cena, vislumbrado no período anterior à terapia.

O remédio para isso é a auto-renovação criativa, como diz Jung (1998, p. 39): a concretização simbólica dos elementos criativos. Para tanto, é necessário o espírito apolíneo: a limitação, a serenidade, o trabalho árduo, que busca uma diferenciação em relação ao coletivo. Apolo representa, simbolicamente, o sonho e a fantasia que, ao ganharem forma pela introspecção aliada à criatividade, propiciam um conhecimento de si mesmo (que se contrapõe à fusão com o coletivo). Para que o apolíneo e o dionisíaco se fundam (o que se dá em O. principalmente através do teatro) ele precisa da religiosidade, como o espiritismo e os fatores mencionados anteriormente (vontade, consecução de objetivos, conhecimento etc.), mas, principalmente, na forma de religio: tem de considerar todos os fatores (ou potências) em seu íntimo para que não seja devassado por eles, e, assim, tenha a possibilidade de unilos, acabando com a coação inerente à separação desses opostos.

O. pressente o caráter religioso desse dionisíaco concretizado na arte quando fala da "magia do teatro, aquela magia superior". Essa concretização efetivada representa, assim, um congraçamento com a fé e pistis na capacidade individual; como concretização simbólica de uma parte de sua personalidade que clama por atenção, representa um passo em direção à totalidade, à individuação - pois toda e qualquer realização de conteúdos da individualidade última que é o Self implica um sentimento religioso e uma construção de significado.

$\mathrm{Na}$ vida de O., parece que esse caráter dionisíaco surgiu com toda força como contraparte ao que viveu na infância: um mundo masculino militaresco, de supressão das emoções, da liberdade e da alegria. A
A falta de concretização simbólica do dionisíaco, que seria possivel através do teatro, causa uma espécie de substituição pelo álcool. 
analogia com a epifania de Dioniso é evidente; ele surge arrasador, e arrasta toda resistência à exaustão com sua loucura e êxtase, liberando a contraparte da ordem rígida estabelecida. O dionisíaco representa, assim, a compensação, o Outro, vivenciadas através de festas, sexualidade e criação, onde o álcool era um componente sempre presente.

Dentro de um diálogo com a Psicologia Social, podemos dizer, portanto, que o problema de O. é tanto individual como social ou cultural. Nascido em uma cultura onde a expressão do dionisíaco é difícil - além da arte, ele aparece geralmente em forma negativa ou inferior - e em uma família também portadora das mesmas dificuldades (talvez em grau até maior), O. foi confrontado com esse problema desde cedo. A força do dionisíaco nele se impôs, mas de maneira caótica, onde a criação e a religiosidade foram aos poucos se afirmando; essa força é proporcional à atração que o álcool, e os problemas decorrentes dessa atração, sempre tiveram sobre ele. A cultura, ou o social, pode ser vista também na maneira com que $\mathrm{O}$. sucumbiu a seus valores: a expectativa de que fosse sempre bem falante, sedutor e extrovertido, sendo mesmo centro das atenções, também é uma expectativa coletiva, além de pessoal, e vem de mãos dadas com uma certa glamurização do álcool e dos efeitos que provoca; da mesma forma ocorreu com a sexualidade, e a tentativa de adequação - principalmente através do álcool - a um mundo (homossexual) do qual não fazia parte, ou, ao menos, não completamente; no caso de O., mundo ou ambiente esse altamente incentivador do hábito de ingerir álcool, vale dizer.

A teoria junguiana fornece um entendimento para os fatores que delineamos aqui. $\mathrm{O}$ dionisíaco representa uma dinâmica psíquica profunda, de ordem arquetípica - e, por isso, sobrepuja, fascina e convence através do numen que lhe é peculiar. $\mathrm{O}$ arquétipo é autônomo, independe da consciência; contudo, a atitude da consciência influi no modo como a dinâmica aparece: quando o ego nega reconhecimento à totalidade do arquétipo (no caso de O., negar o dionisíaco criativo, de realização das emoções, através do uso do álcool como um deus ex machina trágico), este se manifesta como coação e compulsão (como automatismos: a compulsão à ingesta de álcool e os problemas decorrentes). A partir do momento em que a totalidade do dionisíaco é aceita e realizada simbolicamente através da consciência, o próprio telos arquetípico desfaz a coerção e traduz-se na experiência de um sentido: a ingesta compulsiva de álcool diminui, e o sentido do dionisíaco passa a aparecer como uma busca por realização da religiosidadeespiritualidade, da sexualidade e da criação artística.

Retomamos uma das noções de Jung (1938/ 1990, par. 10) de religiosidade: "a atitude particular de uma consciência transformada pela experiência do numinoso". O. vivenciou o numen dionisíaco primeiramente em seu aspecto de coação, através do álcool; a tragédia engendrada por essa coação, transcrita em problemas severos com o álcool, levou-o a uma tentativa de aceitar e ver um sentido nesse numinoso através da arte e da religiosidade. De qualquer forma, ele foi transformado por esse numen, o que caracterizaria o nascimento de uma religiosidade de caráter dionisíaco; entretanto, o desenvolvimento dessa religiosidade ainda está em seus primórdios, ou seja, no inconsciente.

Essa dinâmica arquetípica dionisíaca aparece psiquicamente na forma de símbolos (nos sonhos, a festa, o carnaval, o álcool, a ironia, o Outro). O símbolo é o elemento que possibilita a união de consciente e inconsciente, pois une os opostos. O., ao criar em seu psiquismo e dar a devida atenção e 
consideração (religio) a tais símbolos, possibilita que materiais inconscientes essenciais participem de sua vida. Esses materiais têm suma importância não só porque são partes da totalidade de $\mathrm{O}$. mas também porque são uma compensação a uma cultura e uma religião unilaterais. $\mathrm{O}$ inconsciente busca, assim, transcender, pela confrontação com o indivíduo, a cisão existente na cultura entre cristianismo e dionisíaco. Nesse sentido, ao resgatar uma parte fundamental do homem pela atitude do ego que possibilita uma assimilação desse conteúdo, O. está construindo uma nova síntese de opostos, promotora de totalidade e de vida, cura da cisão - existente tanto no indivíduo, palco do conflito, quanto na cultura. Toda junção de opostos é, portanto, tarefa primariamente do indivíduo, que, assim, cria uma nova realidade existencial: o mundo e a própria vida passam a ser plenos de sentido, em oposição a um racionalismo que pasteuriza tanto a realidade como a experiência de sentido. $\mathrm{O}$ valor dado pelo indivíduo a um significado que percebe como superior terá sempre o caráter de sacro - eficaz e sempre presente contraponto a uma hybris da consciência que assume vários aspectos: racionalismo, estupor alcoólico, grandiosidade artificial e vaidade. O indivíduo encontra-se, assim, protegido de um grandeur artificial (e da conseqüente inferioridade compensatória) que é tanto herança da cultura como dinâmica individual, grandeur que se encontra na gênese da impulsividade coercitiva, fruto do automatismo assumido pelo instinto não contemplado pelo ego e pela cultura, que é cerne dos problemas com o álcool. Em outras palavras, a aceitação de uma instância sentida como superior e plena de sentido representa o remédio para a inflação individual - e também para a inflação coletiva ou da cultura, na medida em que o indivíduo contribui para a formulação do social.

Mas representa ainda mais: a manutenção de uma conexão com a totalidade do inconsciente, através de um entendimento psicológico da questão, sinaliza uma atitude religiosa que é natural ao processo - mas que transcende a mera fé ou crença coletiva; em lugar de ovelha em meio ao rebanho, o indivíduo assume um lugar onde sua religio pessoal sustenta o mundo, na medida em que lhe dá significado. Esse equilíbrio entre eu (o ego) e não-eu (inconsciente ou coletivo), embasado pela religio, constituise na própria meta, ou, em termos junguianos, na individuação.

Passamos, a seguir, à religiosidade descrita como religio. Na acepção de Jung de religio, O. leva uma vida religiosa, pois é um observador cuidadoso tanto de sua vida interior (manifesta por sonhos, fantasias, pensamentos e julgamentos de valor) quanto exterior (comportamentos e atitudes). Religio, nesse sentido, contrapõe-se à pressão pela aceitação social, sendo baseada na liberdade relativa de aceitar os conteúdos do próprio inconsciente - aceitação reforçada pela atração que esses conteúdos exercem sobre a consciência. Em outras palavras, aos valores e significados dados pela cultura (ou seja, o componente da consciência coletiva - que é sempre de inferioridade, segundo Jung, e que faz parte do indivíduo na medida em que este se identifica com aquela) são contrapostos, pela observação cuidadosa, aos valores e significados individuais, aos componentes da individualidade única, dados pelo inconsciente. Esse debate entre o coletivo e o individual dentro do indivíduo é justamente o que Jung chamou de processo de individuação.
Nesse sentido, ao resgatar uma parte fundamental do homem pela atitude do ego que possibilita uma assimilação desse conteúdo, O. está construindo uma nova síntese de opostos, promotora de totalidade e de vida, cura da cisão - existente tanto no indivíduo, palco do conflito, quanto na cultura. 
No caso de O., essa complementaridade entre religião instituída e religio toma uma nova forma. Parece haver uma complementaridade entre a religiosidade dionisíaca e aquela dada pelo espiritismo. Enquanto o dionisíaco toca e representa as bases do inconsciente humano, o mais profundo (o ctônico), e, nesse sentido, caracteriza-se por alegria e tragédia, criação e destruição, o espiritismo é uma religião que busca unir-se a uma espécie de ciência, objetivando um conhecimento - sendo, portanto, de caráter muito mais apolíneo. Dessa forma, além de unir os opostos dionisíaco e apolíneo na arte (o que representa uma forma de religiosidade), $\mathrm{O}$. também os une quando celebra a alegria e o júbilo (em qualquer momento de sua vida) ao mesmo tempo em que segue uma religião instituída caracterizada pelo apolíneo.

\section{Considerações finais}

Cremos ser interessante analisar que contribuição o estudo do caso de O. tem a dar em relação à prática médica e psiquiátrica e ao entendimento dos problemas com o álcool em nossa cultura. É interessante notar que, de acordo com a perspectiva psiquiátrica tradicional, O. teria recebido um diagnóstico de dependência de álcool quando procurou ajuda terapêutica e começou sua análise. Esse diagnóstico, se adotado, teria hipoteticamente, como conseqüências, a adoção de terapia medicamentosa e grupo de auto-ajuda como manejos terapêuticos (visto que, na maior parte dos casos, esse é o procedimento padrão). No entanto, a conseqüência mais grave, talvez, seria a pecha de "alcoólatra" ou alcoolista, que receberia, com todas as suas implicações na terapêutica: abstinência como meta, e não uma diminuição na ingesta, uma moderação no beber, e a maior parte de seus problemas psicológicos, manifestos anteriormente (que estão no cerne de um entendimento dos problemas com o álcool do sujeito, em nosso entendimento - especialmente o problema criativo), seria provavelmente relegada a segundo plano ou sumariamente desconsiderada. Além disso, o confinamento a um determinado grupo (alcoolistas) - ao qual O. sentia não fazer parte - poderia ter reflexos negativos na auto-estima pessoal e na própria avaliação do problema por parte de O., o que influenciaria consideravelmente o resultado de qualquer procedimento terapêutico.

De qualquer forma, à época em que foram feitas as entrevistas, O. já não preenchia critérios nem mesmo para abuso de álcool apesar de (deixando de lado o diagnóstico baseado nas orientações do DSM-IV) ele certamente abusar do álcool freqüentemente, em termos coloquiais. Somente esse fato já testemunha a favor de uma reavaliação dos procedimentos médicos e psicológicos tradicionais.

Concluindo, acreditamos que este trabalho tenha fornecido alguns elementos que afirmam a necessidade, já apontada em outros trabalhos, de avaliar a atenção que o fator religiosidade recebe por parte dos trabalhadores da saúde. Cremos que uma investigação e consideração maiores desse fator seriam de enorme valia, tanto para o entendimento e conseqüente melhora dos problemas (principalmente vinculados ao álcool) apresentados pelos pacientes quanto para a construção de um conhecimento mais abrangente e profundo acerca desses problemas e dos próprios indivíduos. 
BRUNER, J. Atos de Significação. Porto Alegre: Artes Médicas, 1997.

CAMPBELL, D. T. Degrees of Freedom and the Case Study. Comparative Political Studies, v. 8, 1975, pp. 178-193.

CASSIRER, E. Ensaio sobre o Homem: Introdução a uma Filosofia da Cultura Humana. São Paulo: Martins Fontes, 1994.

GEERTZ, C. The Interpretation of Cultures. New York: Basic Books, 1973.

ELIADE, M. The Sacred and Profane. New York: W. R. Trask, 1959.

HEATHER, N. et al. (eds.) The Misuse of Alcohol: Crucial Issues in Dependence, Treatment and Prevention. London: Croom Helm, 1980.

HEATHER, N. (). Más allá del Alcoholismo: Perspectivas Atuales de la Adicción al Alcohol y sus Problemas. Adicciones, v. 11, n. 2,1999, pp. 171-181.

JUNG, C. G. Psicologia e Religião. In Obras Completas de C. G. Jung (Vol. 11i). Petrópolis: Vozes, (1938)1990.

JUNG, C. G. Seminar on Nietzsche’s Zarathustra (abridged ed.). Princeton: Princeton University Press, 1998.

KERÉNYI, K. Dionysus: Archetypal Image of Indestructible Life. Bollingen Series LXV:2. Princeton: Princeton University Press, 1976.

\section{Marlon Xavier}

Professor do Curso de Psicologia da Universidade do Extremo Sul Catarinense - UNESC. Mestre em Psicologia Social pela PUCRS.

Psicólogo clínico de orientação junguiana. Membro do Ambulatório da Cruz Vermelha de Porto Alegre.

Rua Afonso Taunay, 180/621 Boa Vista 90520-540

Porto Alegre - RS

E-mail:marlonx@redemeta.com.br Hudson, 1976a.

The Gods of the Greek. London: Thames and

Apollo: the Wind, the Spirit, and the God. Dallas: Spring Publications, 1983.

OTTO, W. F. Dionysus, Myth and Cult. Dallas: Spring Publications, 1986.

PATTON, M. Q. Qualitative Research and Evaluation Methods Newbury Park: Sage Publications, 1990.

STAKE, R. E. Investigación con Estudio de Casos. Madri: Ediciones Morata, 1998.

TODOROV, T. Mikhail Bakhtin: le Principe Dialogique. Paris: Edition Cuseil, 1981.

VERNANT, J.-P. Mito e Pensamento entre os Gregos: Estudos de Psicologia Histórica. Rio de Janeiro: Paz e Terra, 1990.

VERNANT, J.-P. Mito e Religião na Grécia Antiga. Campinas: Papirus, 1992.

VERNANT, J.-P. O Universo, os Deuses, os Homens. São Paulo: Companhia das Letras, 2000.

YIN, R. Case Study Research: Design and Methods. Thousand Oaks: Sage Publications, 1994. 